\title{
Article \\ Predicting Electrokinetic Coupling and Electrical Conductivity in Fractured Media Using a Fractal Distribution of Tortuous Capillary Fractures
}

\author{
Luong Duy Thanh ${ }^{1,+}+\mathbb{C}_{\text {, Damien Jougnot }}{ }^{2, *,+}{ }^{\mathbb{C}}$, Phan Van Do ${ }^{1}$, Dang Thi Minh Hue ${ }^{1}$ and Tran Thi Chung Thuy ${ }^{1}$ \\ and Vu Phi Tuyen ${ }^{3}$ \\ 1 Thuyloi University, 175 Tay Son, Dong Da, Hanoi, Vietnam; thanh_lud@tlu.edu.vn (L.D.T.); \\ phanvando@tlu.edu.vn (P.V.D.); dtmhue@tlu.edu.vn (D.T.M.H.); tranchungthuy@tlu.edu.vn (T.T.C.T.) \\ 2 Sorbonne Université, CNRS, EPHE, UMR 7619 Metis, F-75005 Paris, France \\ 3 National Institute of Information and Communications Strategy-MIC, Hanoi, Vietnam; \\ tuyenvuphi@gmail.com \\ * Correspondence: damien.jougnot@upmc.fr \\ + These authors contributed equally to this work.
}

Citation: Thanh, L.D.; Jougnot, D.; Van Do, P.; Hue, D.T.M.; Thuy, T.T.C.; Tuyen, V.P. Predicting Electrokinetic Coupling and Electrical Conductivity in Fractured Media Using a Fractal Distribution of Tortuous Capillary Fractures. Appl. Sci. 2021, 11, 5121. https://doi.org/10.3390/app11115121

Academic Editor: Jianbo Gao

Received: 5 March 2021

Accepted: 22 May 2021

Published: 31 May 2021

Publisher's Note: MDPI stays neutral with regard to jurisdictional claims in published maps and institutional affiliations.

Copyright: (c) 2021 by the authors. Licensee MDPI, Basel, Switzerland. This article is an open access article distributed under the terms and conditions of the Creative Commons Attribution (CC BY) license (https:// creativecommons.org/licenses/by/ $4.0 /)$.

\begin{abstract}
Electrokinetics methods have attracted increasing interest to characterize hydrogeological processes in geological media, especially in complex hydrosystems such as fractured formations. In this work, we conceptualize fractured media as a bunch of parallel capillary fractures following the fractal size distribution. This conceptualization permits to obtain analytical models for both the electrical conductivity and the electrokinetic coupling in water saturated fractured media. We explore two different approaches to express the electrokinetic coupling. First, we express the streaming potential coupling coefficient as a function of the zeta potential and then we obtain the effective charge density in terms of macroscopic hydraulic and electrokinetic parameters of porous media. We show that when the surface electrical conductivity is negligible, the proposed models reduces to the previously proposed one based on a bundle of cylindrical capillaries. This model opens up a wide range of applications to monitor the water flow in fractured media.
\end{abstract}

Keywords: fractured media; streaming potential; electrical conductivity; fractal

\section{Introduction}

Among many geophysical methods, electrical conductivity imaging and streaming potential (SP) measurements attract an increasing interest to better understand and monitor water distribution and dynamics in hydrosystems, aquifers, or reservoirs, e.g., [1-3]. These geo-electrical methods are used to detect and monitor groundwater flow, e.g., [4-9], geothermal areas, e.g., [10-12], detection of contaminant plumes, e.g., [13,14], monitoring flow of water in the vadose zone, e.g., $[9,15,16]$ or eco-hydrology, e.g., $[17,18]$. Thanks to accurate petrophysical relationships and advanced hydrogeophysical inversion approaches, these geo-electrical methods can be exploited to estimate hydrogeological parameters of the aquifer, e.g., $[19,20]$. Nevertheless, complex environments such as fractured media and karstic formations remain a challenge for geo-electrical methods.

Even if fractured media constitute a large fraction of hydrosystems, it remains largely under studied. The interest of geo-electrical methods to study fractured media is clearly established in the literature using electrical conductivity, e.g., [21-23] or streaming potential, e.g., $[5,24,25]$, but the quantitative use of these methods remains scarce in the literature.

The nature of fractured media makes it a challenge for integrative methods such as electrical conductivity imaging and streaming potential [26]. Indeed, fractures usually present a huge contrast in terms of properties with the surrounding matrix making it difficult to be clearly identified through diffusion-based methods such as electrical resistivity tomography, e.g., $[27,28]$. Different numerical methods have been proven useful 
for both electrical conductivity and self-potential simulations, among which the very fine discretization in finite-element modelling, e.g., [29,30] or discrete-dual-porosity, e.g., [23,31]. Nevertheless, analytical models and petrophysical relationships can be beneficial to the development and use of geo-electrical methods for faster and simpler approaches.

Petrophysical relationships relating electrical conductivity and structural properties in fractured media are not abundant in the literature. Among other works, Bernabe [32] uses crack networks and percolation to study the transport properties, while Roubinet et al. [33] revisited the classic model of Archie [34] to relate topological and electrical properties. To the best of the authors knowledge, no analytical petrophysical relationships for fractured media exist in the literature.

Regarding the modeling of electrokinetic coupling, the most crucial parameter is the streaming potential coupling coefficient (SPCC). That parameter can be obtained through either the Helmholtz-Smoluchoski (HS) equation or the effective excess charge density approach. The HS equation is commonly used to determine the SPCC via the zeta potential, properties of pore water for a single cylindrical capillary, e.g., [35,36]. Applying a volume averaging procedure, Pride [37] showed that the HS equation is still valid for porous media in case of negligible surface electrical conductivity, see also, [38]. Modified HS equations have been proposed in the literature when the surface conductivity cannot be neglected, e.g., [39-41]. Then, an alternative approach allows the determination of the SPCC via the excess charge that is effectively dragged by the water flow in porous media, e.g., [42-44]. Capillary-based models have been successfully applied to describe SP in porous media, i.e., the porous medium is described as a bundle of parallel cylindrical tubes, e.g., [45-56]. However, microstructure of porous media is normally very complex with tortuous and non-circular pores. Recently, Shi et al. (2018) have theoretically studied the dependence of dynamic electrokinetic coupling coefficient on the electrical double layer thickness for a single cylindrical capillary and a single capillary fracture [57]. Then, they directly extended the obtained electrokinetic coupling coefficient from a single capillary to porous media without applying the upscaling technique. It should be noted that the electroosmosis that is a opposite effect to the SP in porous media has also been studied using capillary bundle models with different capillary geometry such as rectangular, cylindrical and annular geometries, e.g., [58-61]. Nevertheless, to the best of our knowledge, no model has been published to describe both the electrical conductivity an the electrokinetic coupling using a distribution of rectangular (i.e., fracture-like) capillaries.

Therefore, in this work, we conceptualize porous media as a bunch of tortuous parallel fractures or rectangular cross-sections following the fractal pore size distribution to study electrical conductivity and electrokinetic coupling in fractured media. Namely, we develop the model for the SPCC that is expressed in terms of both the zeta potential and the effective charge density. We also propose an analytical model for the effective charge density in terms of macroscopic hydraulic and electrokinetic parameters of porous media. Incidentally, we also obtain an expression for the electrical conductivity of saturated fractured media. All the proposed models are then compared with experimental data available in theliterature and published models.

\section{Theory of the Electrokinetic Coupling}

The streaming current is controlled by the relative movement between the charged solid surfaces and pore fluid and is directly related to an electric double layer (EDL) existing at the interface between the fluid and solid surfaces, e.g., [35]. This streaming current is then balanced out by a conduction current, leading to a so-called streaming potential. The important parameter for SP is the SPCC. At the steady state condition, the SPCC is defined as, e.g., [39]:

$$
C_{S}=\frac{\Delta V}{\Delta P},
$$


where $\Delta V(\mathrm{~V})$ and $\Delta P(\mathrm{~Pa})$ are the generated streaming potential and applied fluid pressure difference, respectively. There normally exist two expressions to determine the SPCC at fully saturated conditions in literature. The first one is the HS equation given by [62]

$$
C_{S}=\frac{\epsilon_{r} \epsilon_{0} \zeta}{\eta \sigma_{w}}
$$

where $\epsilon_{r}$ (no units) is the relative permittivity of the fluid, $\epsilon_{0}(\mathrm{~F} / \mathrm{m})$ is the dielectric permittivity in vacuum, $\zeta$ is the zeta potential, $\eta(\mathrm{Pa} \mathrm{s})$ is the dynamic viscosity, and $\sigma_{w}$ $(\mathrm{S} / \mathrm{m})$ is the electrical conductivity of the fluid. Equation (2) is valid when the surface electrical conductivity of porous media is neglected, e.g., [38]. When the surface electrical conductivity is taken into account, one can apply the modified HS equation given by, e.g., $[36,40,41]$

$$
C_{S}=\frac{\epsilon_{r} \epsilon_{0} \zeta}{\eta\left(\sigma_{w}+2 \frac{\Sigma_{s}}{\Lambda}\right)}
$$

where $\Sigma_{s}(\mathrm{~S})$ is the specific surface conductance and $\Lambda(\mathrm{m})$ is a characteristic length scale [63].

Addition to the HS or modified HS equation, one can express the SPCC via the excess charge density $\widehat{Q}_{v}\left(\mathrm{C} / \mathrm{m}^{3}\right)$ that is dragged by pore water in porous media as, e.g., [42-44]

$$
C_{S}=-\frac{k \widehat{Q}_{v}}{\eta \sigma}
$$

where $k\left(\mathrm{~m}^{2}\right)$ and $\sigma(\mathrm{S} / \mathrm{m})$ are permeability and electrical conductivity of porous materials at fully saturated conditions, respectively.

\section{Theoretical Development}

\subsection{Geometry of Fractured Media}

It has been shown that the fractal geometry can be applied in the analysis of flow and transport properties in porous media in general and specifically in fractured media, e.g., [64-68]. Fractured media are assumed to be composed of the fractures and the surrounding matrix, e.g., [69]. The matrix permeability is normally much smaller than that of the fractures and thus the matrix can be considered as impermeable and no fluid exchange through the fracture walls. In this work, fractures are conceptualized as a bunch of parallel capillary slits as shown in Figure 1. The fracture is approximately considered as plane with rectangular cross-section, whose widths follow the fractal scaling law, e.g., [70-72]. The aperture and width of parallel fractures are $2 a(\mathrm{~m})$ and $w(\mathrm{~m})$, respectively. In order to derive electrokinetic properties at macroscale, a representative elementary volume (REV) as a cube with the length of $L_{o}$ and the cross-sectional area $A_{R E V}$ that is perpendicular to the flow direction is considered as shown in Figure 1. As mentioned, the REV is conceptualized as a bundle of fractures with width varying from $w_{\min }$ to $w_{\max }$. It is shown that the number of fractures whose widths are in the range from $w$ to $w+d w$ in the REV is given by, e.g., [71-74]:

$$
-d N=D_{f} w_{\text {max }}^{D_{f}} w^{-D_{f}-1} d w,
$$

where $D_{f}$ (no units) is the fractal dimension for pore space, $0<D_{f}<2$ in two-dimensional space and $0<D_{f}<3$ in three dimensional space. The minus sign in Equation (5) implies that the number of fractures decreases with an increase of fracture width. The fractal dimension for fracture space $\left(D_{f}\right)$ can be estimated from properties of porous media using the following relation, e.g., [71,72]

$$
D_{f}=2-\frac{\ln \phi}{\ln \alpha}
$$


where $\phi$ is the porosity of porous media and $\alpha$ is the ratio of the minimum width to the maximum width of the fractures $\left(\alpha=w_{\min } / w_{\max }\right)$.

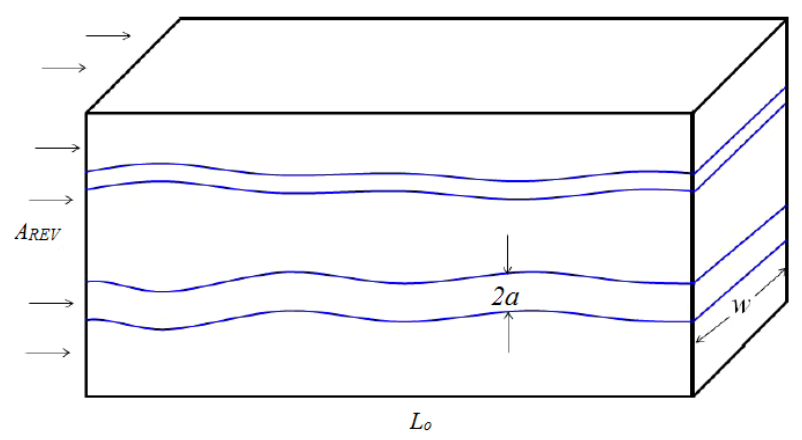

Figure 1. Schematic view of a fractured medium composed of a bunch of parallel slits.

It has been shown that the aperture $a(\mathrm{~m})$ is related to the width $w(\mathrm{~m})$ of the fracture by the following linear scaling law, e.g., [71,72,75,76]:

$$
a=\beta w,
$$

where $\beta$ is the fracture aspect ratio.

\subsection{Hydraulic Properties}

The porosity of the REV can be calculated as the ratio of the total pore volume $V_{p}$ and the total volume $V_{R E V}$ of the REV:

$$
\begin{aligned}
\phi= & \frac{V_{p}}{V_{R E V}}=\frac{\int_{w_{\min }}^{w_{\max }}(2 a w)\left(L_{\tau}\right)(-d N)}{L_{0} A_{R E V}}=\frac{2 \beta \tau D_{f} w_{\max }^{D_{f}}}{A_{R E V}} \int_{w_{\min }}^{w_{\max }} w^{1-D_{f}} d w \\
= & \frac{2 \beta \tau D_{f} w_{\max }^{2}}{A_{R E V}\left(2-D_{f}\right)}\left(1-\alpha^{2-D_{f}}\right),
\end{aligned}
$$

where $L_{o}$ is the length of the REV, $L_{\tau}$ is the real length of the fracture and $\tau=L_{\tau} / L_{o}$ is the dimensionless hydraulic tortuosity of the microfracture, e.g., [77]. For the sake of simplicity, the length of the fractures is assumed to be independent of the fracture width, so an average tortuosity $\tau$ is considered in the model. It is trivial to take into account the correlation between the tortuosity and the capillary size as performed by $[68,78,79]$, for example. However, this extra complexity does not really make the model any more representative of real porous media or affect the key results of the model, e.g., [46].

For a laminar flow, the velocity profile and average velocity (see Figure 2 ) inside the fracture are, respectively, given by, e.g., $[57,80]$

$$
v(y)=\frac{a^{2}}{2 \eta}\left[1-\frac{y^{2}}{a^{2}}\right] \frac{\Delta P}{L_{\tau}}=\frac{a^{2}}{2 \eta \tau}\left[1-\frac{y^{2}}{a^{2}}\right] \frac{\Delta P}{L_{o}},
$$

and

$$
v_{a v}=\frac{a^{2}}{3 \eta \tau} \frac{\Delta P}{L_{0}},
$$

where $\Delta P$ is the fluid pressure difference, $\eta$ is the dynamic viscosity of the fluid, $a$ is the half aperture and $y$ is the coordinate along the aperture as shown in Figure 2. 


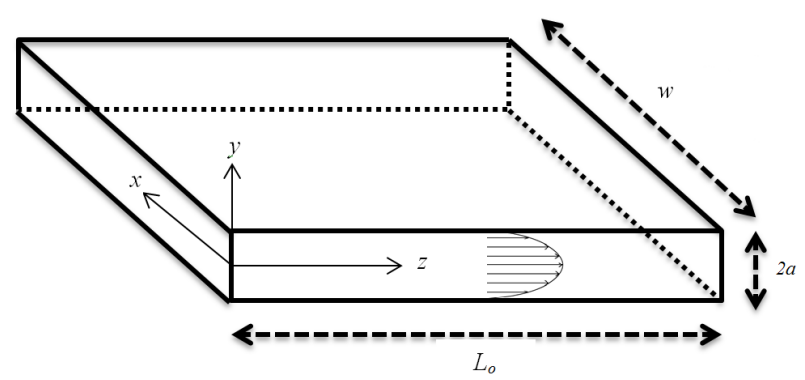

Figure 2. Fluid flow in a fracture and the coordinate along the aperture $\left(a<<w<<L_{o}\right)$.

The flow rate through a fracture is therefore given by

$$
q=v_{a v} \cdot(2 a w)=\frac{2 a^{3} w}{3 \eta \tau} \frac{\Delta P}{L_{o}} .
$$

It is noted that Equation (11) is the well-known cubic law, e.g., [81,82].

Consequently, the total volumetric flow through the REV is the sum of volumetric flow rates through all fractures and is given by:

$$
V_{R E V}=\int_{w_{\min }}^{w_{\max }} q(-d N)
$$

Combining Equations (5), (7), (11) and (12) yields:

$$
\begin{aligned}
V_{R E V}= & \int_{w_{\min }}^{w_{\max }} \frac{a^{2}}{3 \eta \tau} \frac{\Delta P}{L_{o}}(2 a w)\left[D_{f} w_{\max }^{D_{f}} w^{-D_{f}-1} d w\right]= \\
& \frac{2}{3 \eta \tau} D_{f} \beta^{3} w_{\max }^{4} \frac{1-\alpha^{4-D_{f}}}{4-D_{f}} \frac{\Delta P}{L_{o}} .
\end{aligned}
$$

According to Darcy's law (macroscopic scale) for Newtonian fluid flow in porous media, $V_{R E V}$ is expressed as

$$
V_{R E V}=\frac{k A_{R E V}}{\eta} \frac{\Delta P}{L_{o}}
$$

Combining Equations (8), (13) and (14), the following is obtained

$$
k=\frac{\beta^{2} w_{\max }^{2} \phi}{3 \tau^{2}} \frac{1-\alpha^{4-D_{f}}}{4-D_{f}} \frac{2-D_{f}}{1-\alpha^{2-D_{f}}} .
$$

In case of $w_{\max }>>w_{\min }(\alpha \rightarrow 0)$, Equation (15) reduces to

$$
k=\frac{\beta^{2} w_{\max }^{2} \phi}{3 \tau^{2}} \frac{2-D_{f}}{4-D_{f}} .
$$

\subsection{Electrical Conductivity}

Adapting the reported approach for the electrical conductivity in porous media, e.g., $[46,83]$, the bulk conductivity within a single fracture is given by

$$
\sigma_{f b}=\sigma_{w} \frac{2 a w}{A_{R E V} \tau}=\sigma_{w} \frac{2 \beta w^{2}}{A_{R E V} \tau} .
$$

The surface conductivity within a single fracture is given by

$$
\sigma_{f s}=\Sigma_{s} \frac{2 w+4 a}{A_{R E V} \tau}=\Sigma_{s} \frac{2(1+2 \beta) w}{A_{R E V} \tau},
$$


recall that $2 a w$ and $2 w+4 a$ are the cross sectional area and the perimeter of the fracture (see Figure 1). Consequently, the total electrical conductivity in a fracture is given by

$$
\sigma_{f}(w)=\sigma_{f b}+\sigma_{f s}=\sigma_{w} \frac{2 \beta w^{2}}{A_{R E V} \tau}+\Sigma_{s} \frac{2(1+2 \beta) w}{A_{R E V} \tau} .
$$

The electrical conductivity of the REV $\sigma$ under saturated conditions is obtained by integrating over all saturated capillaries as

$$
\sigma=\int_{w_{\min }}^{w_{\max }} \sigma_{f}(w)(-d N)
$$

Combining Equations (5), (19) and (20), the following is obtained

$$
\begin{aligned}
\sigma= & \frac{1}{A_{R E V} \tau}\left\{2 \sigma_{w} \beta D_{f} w_{\max }^{2} \frac{1-\alpha^{2-D_{f}}}{2-D_{f}}+2 \Sigma_{s}(1+2 \beta) D_{f} w_{\max } \frac{1-\alpha^{1-D_{f}}}{1-D_{f}}\right\} . \\
& =\frac{2 \beta D_{f} w_{\max }^{2}\left(1-\alpha^{2-D_{f}}\right)}{A_{R E V}\left(2-D_{f}\right) \tau}\left\{\sigma_{w}+\frac{(1+2 \beta) \Sigma_{s}}{\beta w_{\max }} \frac{2-D_{f}}{1-D_{f}} \frac{1-\alpha^{1-D_{f}}}{1-\alpha^{2-D_{f}}}\right\} .
\end{aligned}
$$

Substituting $A_{R E V}$ from Equation (8) into Equation (21), the electrical conductivity of porous media $\sigma$ under saturated conditions is obtained as

$$
\sigma=\frac{\phi}{\tau^{2}}\left\{\sigma_{w}+\frac{(1+2 \beta) \Sigma_{s}}{\beta w_{\max }} \frac{2-D_{f}}{1-D_{f}} \frac{1-\alpha^{1-D_{f}}}{1-\alpha^{2-D_{f}}}\right\} .
$$

Equation (22) indicates that $\sigma$ of fractured media is related to porosity, electrical conductivity of pore water, specific surface conductance and microstructural parameters of porous media $\left(D_{f}, \phi, \alpha, \beta, w_{\max }\right)$. It has a similar form to published models for porous media, e.g., [37,84-89]. From Equation (22), the formation factor $F$ is deduced as [34]:

$$
F=\lim _{\Sigma_{s} \rightarrow 0}\left(\frac{\sigma_{w}}{\sigma}\right)=\frac{\tau^{2}}{\phi}
$$

Roubinet et al. (2018) conducted a systematic numerical analysis for modeling electrical current flow in complex and heterogeneous fractured rocks [33]. For simple case of a simple fracture-matrix system with $N_{f}$ horizontal fractures embedded in a matrix having domain size $L(\tau=1)$, fracture aperture $b_{f}$ and matrix porosity $\phi_{b}$, the formation factor of such a domain is given by [33]

$$
F=\frac{L}{\left[N_{f} b_{f}+\left(L-N_{f} b_{f}\right) \phi_{b}^{m_{b}}\right]},
$$

where $m_{b}$ is the cementation factor for the matrix. If a matrix is impervious to electrical current, that is, $\phi_{b}=0$, for which the porosity only depends on the fractures as $\phi=N_{f} b_{f} / L$, Equation (24) now becomes for fractured media $F=\phi^{-1}$. This is expected from simple geometry principles, as for parallel straight and horizontal capillaries with no surface conductivity: $\sigma=\phi \sigma_{w}$.

Equation (22) can be rewritten as:

$$
\sigma=\frac{1}{F}\left\{\sigma_{w}+\frac{(1+2 \beta) \Sigma_{s}}{\beta w_{\max }} \frac{2-D_{f}}{1-D_{f}} \frac{1-\alpha^{1-D_{f}}}{1-\alpha^{2-D_{f}}}\right\} .
$$




\subsection{Streaming Potential Coupling Coefficient}

\subsubsection{Streaming Current in the REV}

Adapting the strategy given by [90], the streaming current in a fracture due to transport of charge by the fluid under a fluid pressure difference is given by

$$
i_{s}(a)=\int_{-a}^{+a} v(y) \bar{Q}_{v}(y)(w \cdot d y),
$$

where $a$ is the half aperture and $y$ is the coordinate along the aperture as shown in Figure 2, $v(y)(\mathrm{m} / \mathrm{s})$ is the velocity profile given by Equation $(9)$ and $\bar{Q}_{v}(y)\left(\mathrm{C} / \mathrm{m}^{3}\right)$ is the charge distribution in a fracture. Under Debye-Hückel approximation and the fluid of a binary symmetric $1: 1$ electrolyte, e.g., [ 51,91$], \bar{Q}_{v}(y)$ is given by, e.g., [57,92]

$$
\bar{Q}_{v}(y)=-\frac{\epsilon_{r} \epsilon_{o} \zeta}{\lambda^{2}} \frac{\cosh \left(\frac{y}{\lambda}\right)}{\cosh \left(\frac{a}{\lambda}\right)}
$$

where $\lambda$ is the Debye length depending on properties of the fluid and not on properties of the solid surfaces, e.g., $[36,93]$.

Combining Equations (9), (26) and (27), one obtains

$$
i_{s}(a)=-\frac{\epsilon_{r} \epsilon_{o} \zeta}{\eta} \frac{2 w a}{\tau}\left[1-\frac{\lambda}{a} \tanh \left(\frac{a}{\lambda}\right)\right] \frac{\Delta P}{L_{0}}
$$

Under most environmental conditions, ionic strengths (i.e., a proxy for ionic concentration) in potable water are normally between $10^{-3}$ and $10^{-2} \mathrm{~mol} / \mathrm{L}$ [94]. Reservoirs can be saturated with brine with much higher ionic concentrations. Therefore, the Debye length is typically less than $10 \mathrm{~nm}$ at $25^{\circ} \mathrm{C}$ [93]. In addition, typical characteristic size of pore and fracture aperture in geological media is tens of micrometer, e.g., [95]. Therefore, the Debye length is normally much smaller than the pore sizes (thin EDL assumption). As seen in Figure 3 , when $a$ is 20 times larger than $\lambda, 1-\frac{\lambda}{a} \tanh \left(\frac{a}{\lambda}\right)$ can be approximated as 1 with around 5\% difference (see the red dot in Figure 3). Under that condition, Equation (28) is simplified to

$$
i_{s}(w)=-\frac{\epsilon_{r} \epsilon_{o} \zeta}{\eta} \frac{2 w a}{\tau} \frac{\Delta P}{L_{0}}=-\frac{\epsilon_{r} \epsilon_{o} \zeta}{\eta} \frac{2 \beta w^{2}}{\tau} \frac{\Delta P}{L_{0}} .
$$

Therefore, the total streaming current through the REV is given by, e.g., $[53,56]$

$$
I_{s}=\int_{w_{\min }}^{w_{\max }} i_{s}(w)(-d N)
$$

Combining Equations (5), (29) and (30) yields

$$
I_{s}=-\frac{2 \epsilon_{r} \epsilon_{o} \zeta}{\eta \tau} \frac{\Delta P}{L_{0}}\left(\beta D_{f} w_{\max }^{D_{f}}\right) \int_{w_{\min }}^{w_{\max }} w^{1-D_{f}} d w=-\frac{2 \epsilon_{r} \epsilon_{o} \zeta \beta D_{f}}{\eta \tau} \frac{w_{\max }^{2}}{\left(2-D_{f}\right)}\left(1-\alpha^{2-D_{f}}\right) \frac{\Delta P}{L_{0}},
$$

recall that $\alpha=w_{\min } / w_{\max }$.

\subsubsection{Conduction Current in the REV}

The streaming current is responsible for the streaming potential $\Delta V$ that is set up across porous media under a fluid flow. This streaming potential will generate an electric conduction current that is opposite in direction with the streaming current. According to Ohm's law, the electrical conduction current density is given by

$$
J_{c}=\sigma \frac{\Delta V}{L_{o}},
$$


recall that $\sigma$ is the electrical conductivity of the REV that has been previously presented. Therefore, the total electrical conduction current through the REV is given by

$$
I_{c}=J_{c} A_{R E V}
$$

Combining Equations (21), (32) and (33), the following is obtained

$$
I_{c}=\frac{2 \beta D_{f} w_{\max }^{2}\left(1-\alpha^{2-D_{f}}\right)}{\left(2-D_{f}\right) \tau}\left\{\sigma_{w}+\frac{(1+2 \beta) \Sigma_{s}}{\beta w_{\max }} \frac{2-D_{f}}{1-D_{f}} \frac{1-\alpha^{1-D_{f}}}{1-\alpha^{2-D_{f}}}\right\} \frac{\Delta V}{L_{o}} .
$$

\subsubsection{Streaming Potential Coupling Coefficient}

At steady state, the total electrical current through the REV is zero and one obtains

$$
I_{S}+I_{c}=0 .
$$

Combining Equations (31), (34) and (35) yields

$$
\Delta V=\frac{\epsilon_{r} \epsilon_{0} \zeta \Delta P}{\eta\left[\sigma_{w}+\frac{(1+2 \beta) \Sigma_{s}}{\beta w_{\max }} \frac{2-D_{f}}{1-D_{f}} \frac{1-\alpha^{1-D_{f}}}{1-\alpha^{2-D_{f}}}\right]} .
$$

Consequently, the SPCC is obtained as

$$
C_{S}=\frac{\Delta V}{\Delta P}=\frac{\epsilon_{r} \epsilon_{0} \zeta}{\eta\left[\sigma_{w}+\frac{(1+2 \beta) \Sigma_{s}}{\beta w_{\max }} \frac{2-D_{f}}{1-D_{f}} \frac{1-\alpha^{1-D_{f}}}{1-\alpha^{2-D_{f}}}\right]} .
$$

Equation (37) indicates that the SPCC for fractured media under fully saturated conditions is related to the zeta potential, fluid properties, specific surface conductance at the solid water interface and microstructural properties of the media $\left(D_{f}, \alpha, w_{\max }\right.$ and $\left.\beta\right)$. When $\Sigma_{s}=0$, Equation (37) reduces to the HS equation as shown by Equation (2). It is indicated that for negligible surface conductivity, the SPCC is independent of fracture size distribution and geometrically shaped pore structures.

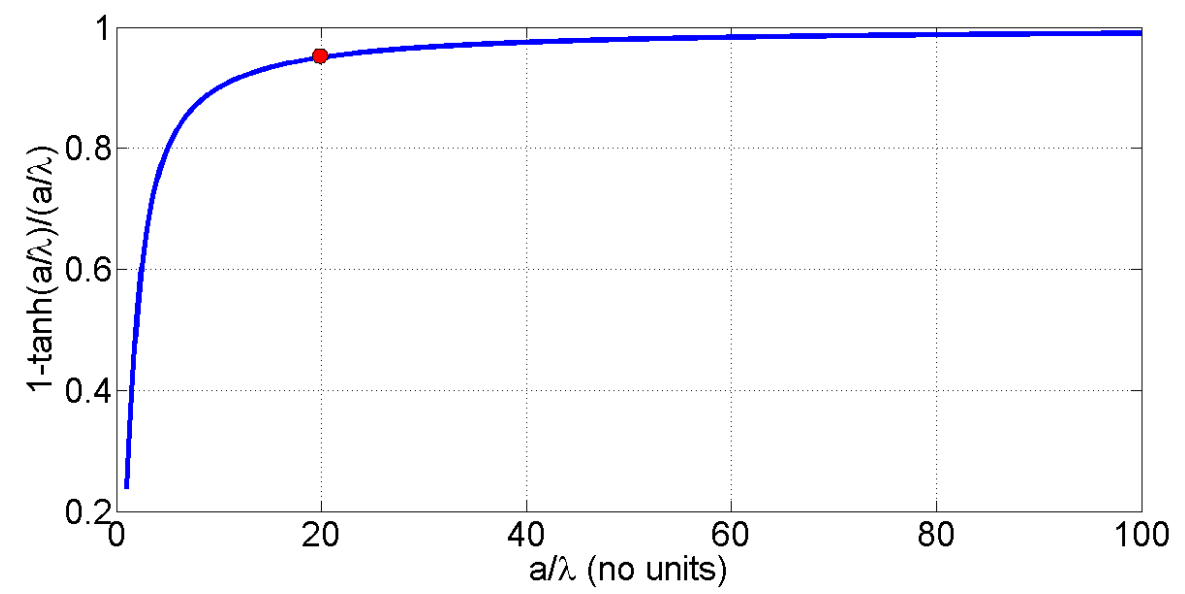

Figure 3. The variation of $\left[1-\frac{\lambda}{a} \tanh \left(\frac{a}{\lambda}\right)\right]$ with $a / \lambda$.

Comparing Equations (3) and (37), the characteristic length scale $\Lambda(\mathrm{m})$ is obtained for fractured media as

$$
\Lambda=w_{\max } \frac{2 \beta\left(1-D_{f}\right)\left(1-\alpha^{2-D_{f}}\right)}{(1+2 \beta)\left(2-D_{f}\right)\left(1-\alpha^{1-D_{f}}\right)} .
$$


It should be noted that Thanh et al. (2020) [56] and Rembert et al. (2020) [96] also obtained expressions for the characteristic length scale in porous media.

\subsection{Effective Excess Charge Density}

Following the formalism presented by [52] or [54], we determine the effective excess charge density $\widehat{Q}_{v}\left(\mathrm{C} / \mathrm{m}^{3}\right)$ carried by the water flow in the REV. The effective excess charge density $\widehat{Q}_{v}^{w}\left(\mathrm{C} / \mathrm{m}^{3}\right)$ carried by the water flow in a single fracture with the width of $w$ and aperture of $2 a$ is defined by, e.g., [50,52,54]:

$$
\widehat{Q}_{v}^{w}=\frac{1}{v_{a v}(2 a w)} \int_{-a}^{+a} \bar{Q}_{v}(y) v(y)(w \cdot d y),
$$

recall that $v(y), v_{a v}$ and $\bar{Q}_{v}(y)$ is the velocity profile, the average velocity and the charge distribution in the fracture, respectively. Their expressions are presented in Equations (9), (10) and (27), respectively. Combining Equations (9), (10), (27) and (39), one obtains

$$
\widehat{Q}_{v}^{w}=-\frac{3 \epsilon_{r} \epsilon_{o} \zeta}{\beta^{2} w^{2}}\left[1-\frac{\lambda}{a} \tanh \left(\frac{a}{\lambda}\right)\right]
$$

Under a thin EDL condition, Equation (40) may be simplified as

$$
\widehat{Q}_{v}^{w}=-\frac{3 \epsilon_{r} \epsilon_{o} \zeta}{\beta^{2} w^{2}}
$$

The effective excess charge $\widehat{Q}_{v}\left(\mathrm{C} / \mathrm{m}^{3}\right)$ carried by the water flow in the REV is defined by, e.g., $[50,52]$ :

$$
\begin{aligned}
\widehat{Q}_{v}= & \frac{1}{v_{D} A_{R E V}} \int_{w_{\text {min }}}^{w_{\max }} \widehat{Q}_{v}^{w} v_{a v}(2 a w)(-d N) \\
& =-\frac{1}{v_{D} A_{R E V}} \frac{2 \epsilon_{r} \epsilon_{o} \zeta \beta D_{f} w_{\max }^{2}}{\eta \tau} \frac{\left(1-\alpha^{2-D_{f}}\right)}{2-D_{f}} \frac{\Delta P}{L_{o}},
\end{aligned}
$$

where $A_{R E V}$ is the cross-section area of the REV perpendicular to the flow direction and $v_{D}$ is the Darcy's velocity $(\mathrm{m} / \mathrm{s})$ that is given by

$$
v_{D}=\frac{k}{\eta} \frac{\Delta P}{L_{0}}
$$

recall that $k$ is the permeability of porous media.

Combining Equations (42) and (43), the following is obtained:

$$
\widehat{Q}_{v}=-\frac{2 \epsilon_{r} \epsilon_{o} \zeta \beta D_{f} w_{\max }^{2}}{\tau k A_{R E V}} \frac{\left(1-\alpha^{2-D_{f}}\right)}{2-D_{f}}
$$

Substituting $A_{R E V}$ from Equation (8) into Equation (44), $\widehat{Q}_{v}$ in the REV is written as

$$
\widehat{Q}_{v}=-\epsilon_{r} \epsilon_{o} \zeta \frac{\phi}{\tau^{2} k} .
$$

Equation (45) shows the relationship between $\widehat{Q}_{v}$, macroscopic hydraulic parameters of porous media (the permeability, porosity, tortuosity) and electrokinetic parameters (the zeta potential). It is seen that the fracture size distribution and geometrically shaped fracture structures $\left(w_{\max }, \alpha\right.$ and $\beta$ ) do not directly appear in the closed-form equation for $\widehat{Q}_{v}$ as reported in literature, e.g., [52,94]. Note that Equation (45) shows a behavior that is completely consistent with the empirical relationship proposed by [19]. To obtain the 
dependence of $\widehat{Q}_{v}$ on the parameters of $w_{\max }, \alpha$ and $\beta$, we combine Equations (15) and (45) to get the following:

$$
\widehat{Q}_{v}=-\epsilon_{r} \epsilon_{o} \zeta \frac{3\left(4-D_{f}\right)\left(1-\alpha^{2-D_{f}}\right)}{\beta^{2} w_{\text {max }}^{2}\left(2-D_{f}\right)\left(1-\alpha^{4-D_{f}}\right)} .
$$

Comparing Equations (21), (37) and (44), one can find the SPCC from $\widehat{Q}_{v}$ as

$$
C_{S}=-\frac{k \widehat{Q}_{v}}{\eta \sigma} .
$$

Equation (47) is the same as Equation (4) that has been developed for porous media using the volume averaging procedure, e.g., $[43,97]$. However, Equation (47) is here explicitly developed from the assumptions made for fractured media. This confirms the findings of $[47,48,94]$, the coupling coefficient dependence to the pore space geometry (pore size distribution and pore shapes) can be taken into account in the effective excess charge density $\widehat{Q}_{v}$.

\section{Results and Discussion}

Figure 4 shows the variation of the permeability of fractured media $k$ with the fracture aspect ratio $\beta$ and porosity $\phi$ predicted from Equation (15) for three values of the ratio of minimum to maximum apertures $\alpha(0.0001,0.001$ and 0.01$)$ with representative values of $w_{\max }=200 \times 10^{-6} \mathrm{~m}, \tau=1.2$ : (a) $\phi$ is fixed at 0.15 and (b) $\beta$ is fixed at 0.001 . Note that we determine $D_{f}$ from $\phi$ and $\alpha$ using Equation (6). It is seen that the permeability increases with an increase of $\phi$ as reported in literature for fractured rocks, e.g., [74,98-100]. It can be explained by the fact that larger porosity means larger space occupied by fractures leading to larger permeability. Additionally, Figure 4 also shows that the permeability increases with an increase of $\beta$ and $\alpha$. The reason for the increase of $k$ with an increase of $\beta$ may be that larger the fracture aspect ratio leads to higher flow rate and therefore higher permeability. The increase of $k$ with an increase of $\alpha$ can be explained by the increase of the average fracture aperture with $\alpha$ as shown by [74].

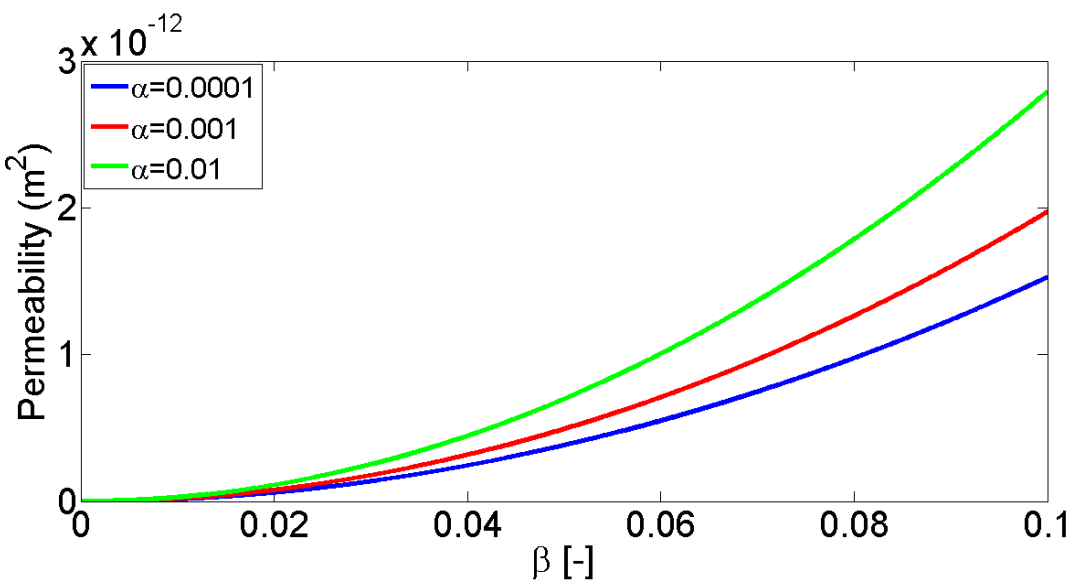

(a)

Figure 4. Cont. 


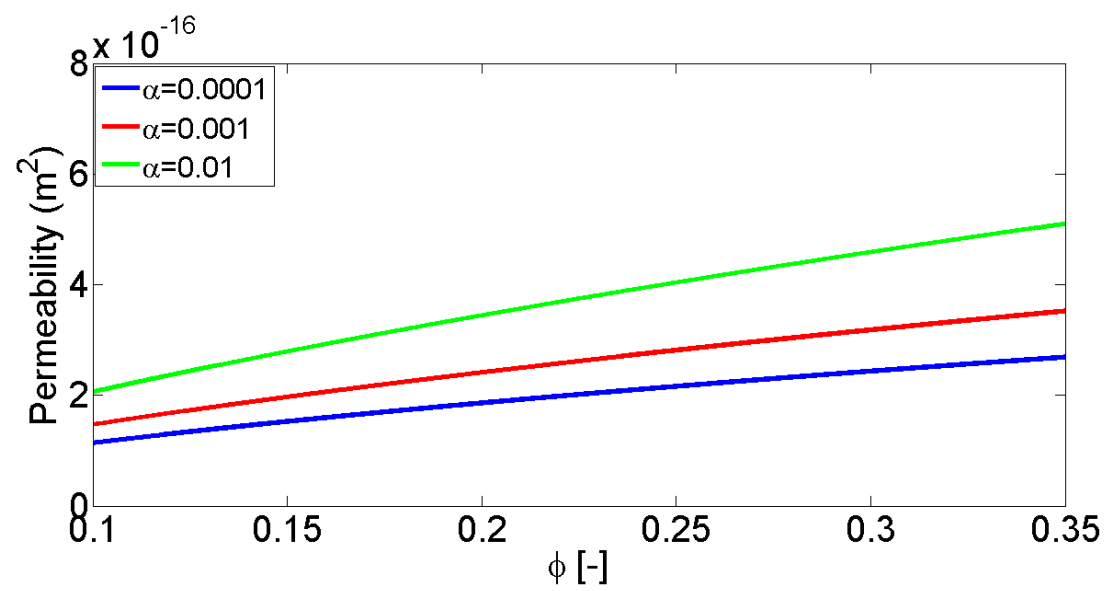

(b)

Figure 4. The variation of the permeability of fractured media $k$ with the fracture aspect ratio $\beta$ and porosity $\phi$ predicted from Equation (15) for three values of $\alpha(0.0001,0.001$ and 0.01$)$ with representative values of $w_{\max }=200 \times 10^{-6} \mathrm{~m}, \tau=1.2$ : (a) $\phi$ is fixed at 0.15 ; (b) $\beta$ is fixed at 0.001 .

Figure 5 shows the variation of the electrical conductivity of fractured media $\sigma$ with the fracture aspect ratio $\beta$ and the fractal dimension of the fracture sizes $D_{f}$ for three values of $\alpha(0.0001,0.001$ and 0.01$)$ with representative values of $\sigma_{w}=10^{-2} \mathrm{~S} / \mathrm{m}, \Sigma_{s}=1.5 \times 10^{-9} \mathrm{~S}$, $F=20$ and $w_{\max }=200 \times 10^{-6} \mathrm{~m}$ : (a) $D_{f}$ is fixed at 1.7 and (b) $\beta$ is fixed at 0.001 . It is seen that the $\sigma$ is very sensitive with $\beta, D_{f}$ and $\alpha$. For given values of $D_{f}$ and $\alpha, \sigma$ decreases with an increase of $\beta$. It can be explained by the decrease of the surface conductivity when $\beta$ increases. Additionally, $\sigma$ increases with an increase of $D_{f}$ and with a decrease of $\alpha$. That can be explained by an increase of the total number of fractures in the REV and therefore, the increase of surface conductivity with the increase of $D_{f}$ and with the decrease of $\alpha$ (e.g., see [74] for more details).

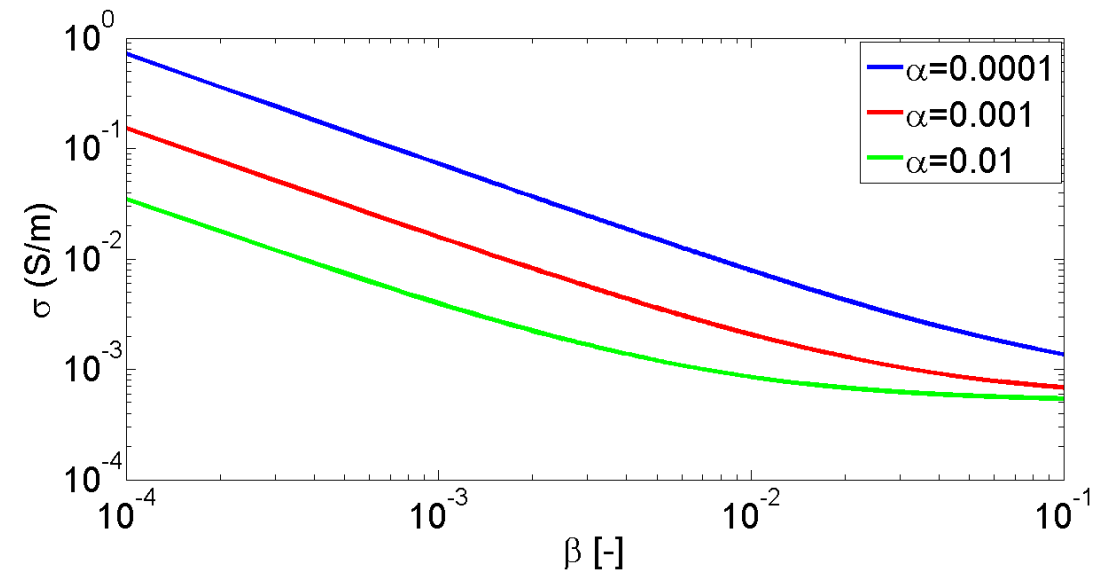

(a)

Figure 5. Cont. 


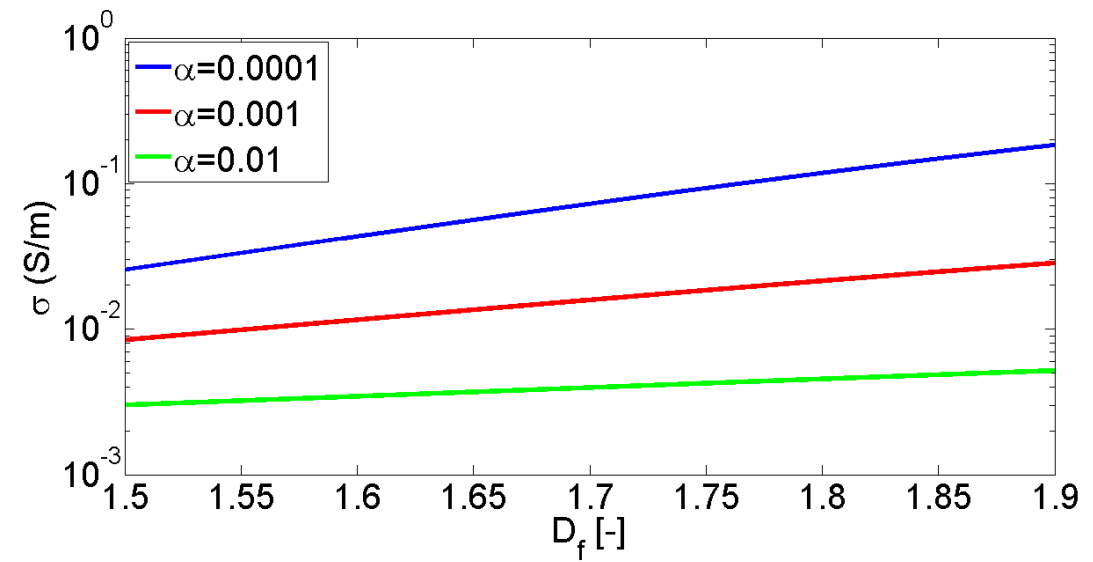

(b)

Figure 5. The variation of $\sigma$ with the fracture aspect ratio $\beta$ and the fractal dimension of the fracture sizes $D_{f}$ predicted from Equation (25) for three values of $\alpha(0.0001,0.001$ and 0.01$)$ with representative values of $\sigma_{w}=5 \times 10^{-2} \mathrm{~S} / \mathrm{m}, \Sigma_{s}=1 \times 10^{-9} \mathrm{~S}, F=20$ and $w_{\max }=200 \times 10^{-6} \mathrm{~m}$. (a) $D_{f}$ is fixed at 1.7. (b) $\beta$ is fixed at 0.001 .

Figure 6 predicts the variation of the SPCC with the fracture aspect ratio $\beta$ and the maximum width $w_{\max }$ predicted from Equation (37) for three values of $\alpha(0.0001,0.001$ and 0.01) with representative values of $\sigma_{w}=2 \times 10^{-2} \mathrm{~S} / \mathrm{m}, \Sigma_{s}=1 \times 10^{-9} \mathrm{~S}, \zeta=-30 \mathrm{mV}$, $\phi=0.15$ : (a) $w_{\text {max }}$ is fixed at $200 \times 10^{-6} \mathrm{~m}$ and (b) $\beta$ is fixed at 0.001 . Similarly to previously mentioned, the value of $D_{f}$ is determined from Equation (6) with the knowledge of $\phi$ and $\alpha$. It is seen that the SPCC in magnitude increases with an increase of $\beta$ for a given value of $\alpha$. Additionally, one can see that when $\alpha$ increases, the SPCC also increases. The reason is that $\sigma$ decreases with an increase of $\beta$ and with increase of $\alpha$. As deduced from Equations (25) and (37), when $\sigma$ decreases then the SPCC increases. The prediction also shows that the SPCC increases with an increase of $w_{\max }$. This may be attributed to the fact that a larger fracture size leads to a lower surface electrical conductivity and therefore an increase of the SPCC. When $w_{\max }$ exceeds a certain value, the SPCC becomes independent of fracture sizes. The reason is that the surface electrical conductivity can be negligible at large fracture sizes as indicated by Equation (22).

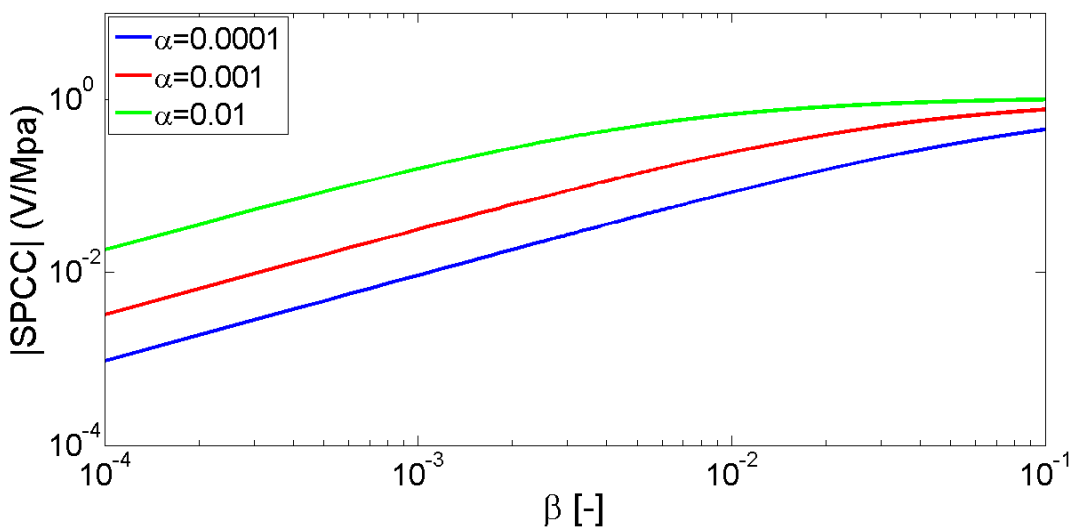

(a)

Figure 6. Cont. 


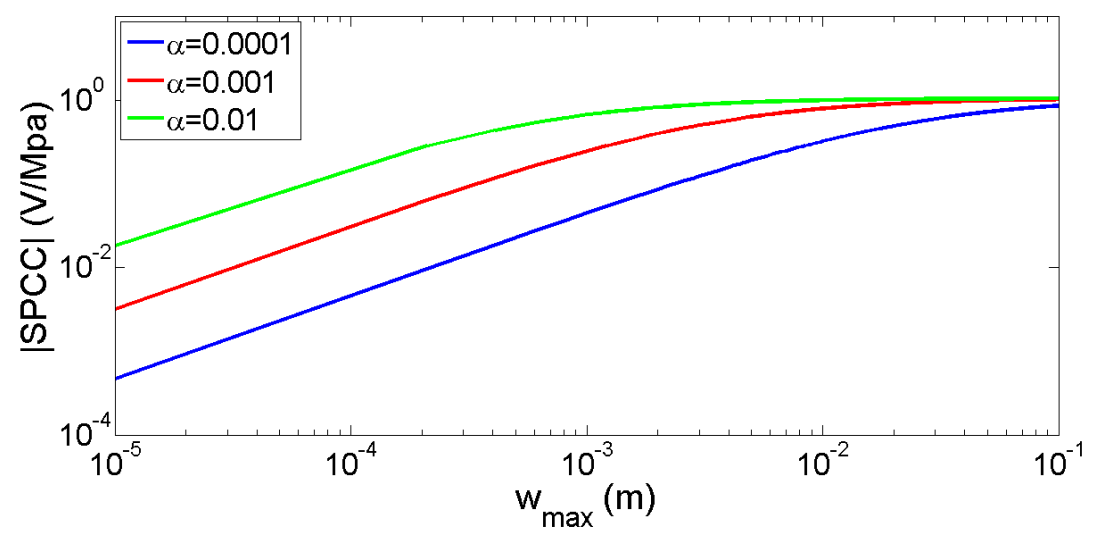

(b)

Figure 6. The variation of the SPCC with the fracture aspect ratio $\beta$ and the maximum width $w_{\max }$ predicted from Equation (37) for three values of $\alpha(0.0001,0.001$ and 0.01$)$ with representative values of $\sigma_{w}=2 \times 10^{-2} \mathrm{~S} / \mathrm{m}, \Sigma_{s}=1 \times 10^{-9} \mathrm{~S}, \zeta=-30 \mathrm{mV}, \phi=0.15$ : (a) $w_{\max }$ is fixed at $200 \times 10^{-6} \mathrm{~m}$ and (b) $\beta$ is fixed at 0.001 .

Figure 7 shows the variation of the $\widehat{Q}_{v}$ with the fracture aspect ratio $\beta$ predicted from Equation (46) for three values of $\alpha(0.0001,0.001$ and 0.01$)$ with representative values of $\sigma_{w}=2 \times 10^{-2} \mathrm{~S} / \mathrm{m}, \Sigma_{s}=1 \times 10^{-9} \mathrm{~S}, \zeta=-30 \mathrm{mV}, \phi=0.15$ and $w_{\max }=200 \times 10^{-6} \mathrm{~m}$. It is seen that the $\widehat{Q}_{v}$ decreases with an increase of $\beta$ and increase of $\alpha$. As shown in Figure 4 the permeability $k$ increases with increasing $\beta$ or $\alpha$. That is in good match with results reported in [19] or [101] in which the $\widehat{Q}_{v}$ decreases with an increase of permeability $k$ for porous media.

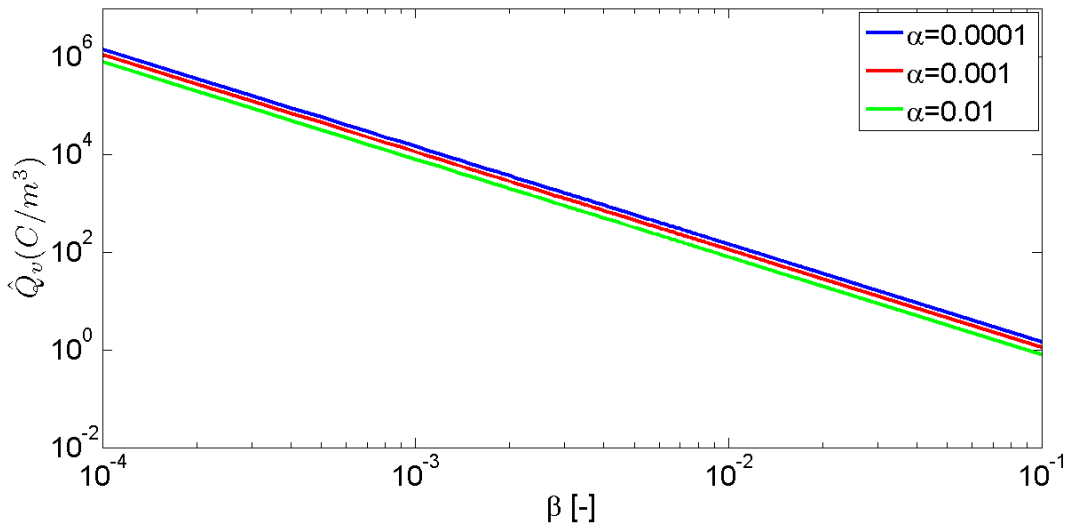

Figure 7. The variation of the $\widehat{Q}_{v}$ with the fracture aspect ratio $\beta$ predicted from Equation (46) for three values of $\alpha(0.0001,0.001$ and 0.01$)$.

Due to lack of experimental data for fractured media, the model result is only compared with the experimental data published by [102] for three fractured limestones from different depths (samples A, B and C). The permeability, porosity and maximum width of fractured samples A, B and C are reported to be $1 \times 10^{-17} \mathrm{~m}^{2}, 0.007,80 \mu \mathrm{m} ; 4.69 \times 10^{-16} \mathrm{~m}^{2}$, $0.0107,200 \mu \mathrm{m}$ and $4.8 \times 10^{-17} \mathrm{~m}^{2}, 0.006,150 \mu \mathrm{m}$, respectively. Figure 8 shows the comparison between the model result from Equation (16) with the measured data for samples $\mathrm{A}, \mathrm{B}$ and $\mathrm{C}$. For the comparison, the model parameters $\beta, \tau$ and $D_{f}$ are determined by seeking a minimum root-mean-square error (RMSE) through the "fminsearch" function in the MATLAB. We found $\beta=0.009, \tau=1.5$ and $D_{f}=1.8$ to give the minimum RMSE for fractured samples. Note that Ghanbarian et al. (2019) found the values of $\beta$ between 0.1 and 0.001 by fitting their model to experimental data of tensile fractures in the Krafla fissure swarm of northeast Iceland [76]. Besides the 1:1 line (the solid line), the 1:10 and the 10:1 lines are also shown in Figure 8 (the dashed lines). It is seen that the model predicts well the experimental data within less than 1 order of magnitude. Nevertheless, 
additional experimental laboratory studies or well controlled field measurements should be conducted to test our model further.

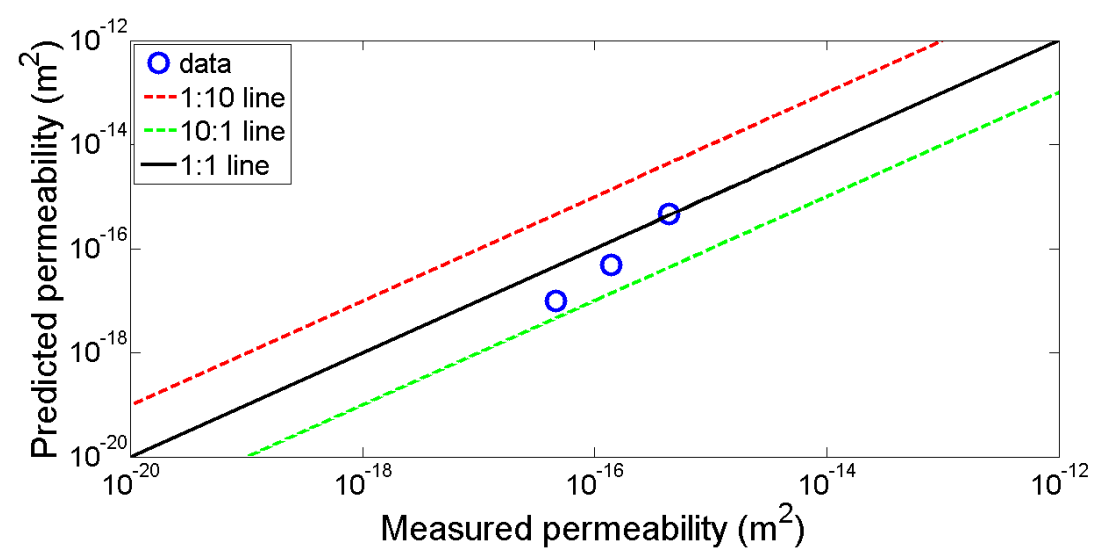

Figure 8. Comparison between measured permeability and calculated one for three fractured limestone samples obtained from [102] using Equation (16).

\section{Conclusions}

In this work, we conceptualize porous media as a bunch of parallel capillary fractures following a fractal pore size distribution to obtain the model for both electrical conductivity and SPCC. The later is expressed in terms of both the zeta potential and the effective charge density. We also propose an analytical model originating from the effective charge density approach that depends on macroscopic hydraulic and electrokinetic parameters of porous media. This work shows that when the surface electrical conductivity can be neglected, the proposed models reduces to ones obtained by a volume averaging procedure or a cylindrical capillary bundle model. It means that, in saturated conditions, the proposed models do not depend on the pore size distribution and geometrically shaped pore structures $\left(w_{\max }, \alpha\right.$ and $\left.\beta\right)$. We believe that the models proposed in this work can open-up new possibilities to study and monitor water flow in fractured media.

Author Contributions: Conceptualization, L.D.T. and D.J.; methodology, L.D.T. and D.J.; formal analysis, L.D.T., D.J., P.V.D., D.T.M.H., T.T.C.T., V.P.T.; investigation, L.D.T., D.J.; data curation, L.D.T., D.J.; writing—original draft preparation, L.D.T. and D.J.; writing—review and editing, L.D.T., D.J., P.V.D., D.T.M.H., T.T.C.T., V.P.T. All authors have read and agreed to the published version of the manuscript.

Funding: Vietnam National Foundation for Science and Technology Development (NAFOSTED) under grant number 103.99-2019.316.

Acknowledgments: The authors thanks the editor and the three reviewers for their nice comments.

Conflicts of Interest: The authors declare no conflict of interest.

\section{References}

1. Revil, A.; Karaoulis, M.; Johnson, T.; Kemna, A. Review: Some low-frequency electrical methods for subsurface characterization and monitoring in hydrogeology. Hydrogeol. J. 2012, 20, 617-658. [CrossRef]

2. Binley, A.; Hubbard, S.S.; Huisman, J.A.; Revil, A.; Robinson, D.A.; Singha, K.; Slater, L.D. The emergence of hydrogeophysics for improved understanding of subsurface processes over multiple scales. Water Resour. Res. 2015, 51, 3837-3866. [CrossRef]

3. Parsekian, A.D.; Singha, K.; Minsley, B.J.; Holbrook, W.S.; Slater, L. Multiscale geophysical imaging of the critical zone. Rev. Geophys. 2015, 53, 1-26. [CrossRef]

4. Jouniaux, L.; Pozzi, J.; Berthier, J.; Massé, P. Detection of fluid flow variations at the Nankai Trough by electric and magnetic measurements in boreholes or at the seafloor. J. Geophys. Res. 1999, 104, 29293-29309. [CrossRef]

5. Fagerlund, F.; Heinson, G. Detecting subsurface groundwater flow infractured rock using self-potential (SP) methods. Environ. Geol. 2003, 43, 782-794. [CrossRef]

6. Titov, K.; Revil, A.; Konosavsky, P.; Straface, S.; Troisi, S. Numerical modelling of self-potential signals associated with a pumping test experiment. Geophys. J. Int. 2005, 162, 641-650. [CrossRef] 
7. Aizawa, K.; Ogawa, Y.; Ishido, T. Groundwater flow and hydrothermal systems within volcanic edifices: Delineation by electric self-potential and magnetotellurics. J. Geophys. Res. 2009, 114. [CrossRef]

8. Singha, K.; Gorelick, S.M. Saline tracer visualized with three-dimensional electrical resistivity tomography: Field-scale spatial moment analysis. Water Resour. Res. 2005, 41. [CrossRef]

9. Daily, W.; Ramirez, A.; LaBrecque, D.; Nitao, J. Electrical resistivity tomography of vadose water movement. Water Resour. Res. 1992, 28, 1429-1442. [CrossRef]

10. Finizola, A.; Lenat, N.; Macedo, O.; Ramos, D.; Thouret, J.; Sortino, F. Fluid circulation and structural discontinuities inside misti volcano (peru) inferred from sel-potential measurements. J. Volcanol. Geotherm. Res. 2004, 135, 343-360. [CrossRef]

11. Mauri, G.; Williams-Jones, G.; Saracco, G. Depth determinations of shallow hydrothermal systems by self-potential and multi-scale wavelet tomography. J. Volcanol. Geotherm. Res. 2010, 191, 233-244. [CrossRef]

12. Soueid Ahmed, A.; Revil, A.; Byrdina, S.; Coperey, A.; Gailler, L.; Grobbe, N.; Viveiros, F.; Silva, C.; Jougnot, D.; Ghorbani, A.; et al. 3D electrical conductivity tomography of volcanoes. J. Volcanol. Geotherm. Res. 2018, 356, 243-263. [CrossRef]

13. Martinez-Pagan, P.; Jardani, A.; Revil, A.; Haas, A. Self-potential monitoring of a salt plume. Geophysics 2010, 75, WA17-WA25. [CrossRef]

14. Naudet, V.; Revil, A.; Bottero, J.Y.; Bégassat, P. Relationship between self-potential (SP) signals and redox conditions in contaminated groundwater. Geophys. Res. Lett. 2003, 30. [CrossRef]

15. Doussan, C.; Jouniaux, L.; Thony, J.L. Variations of self-potential and unsaturated water flow with time in sandy loam and clay loam soils. J. Hydrol. 2002, 267, 173-185. [CrossRef]

16. Jougnot, D.; Linde, N.; Haarder, E.; Looms, M. Monitoring of saline tracer movement with vertically distributed self-potential measurements at the HOBE agricultural test site, Voulund, Denmark. J. Hydrol. 2015, 521, 314-327. [CrossRef]

17. Mares, R.; Barnard, H.R.; Mao, D.; Revil, A.; Singha, K. Examining diel patterns of soil and xylem moisture using electrical resistivity imaging. J. Hydrol. 2016, 536, 327-338. [CrossRef]

18. Voytek, E.B.; Barnard, H.R.; Jougnot, D.; Singha, K. Transpiration- and precipitation-induced subsurface water flow observed using the self-potential method. Hydrol. Process. 2019, 33, 1784-1801. [CrossRef]

19. Jardani, A.; Revil, A.; Boleve, A.; Crespy, A.; Dupont, J.P.; Barrash, W.; Malama, B. Tomography of the Darcy velocity from self-potential measurements. Geophys. Res. Lett. 2007, 34. [CrossRef]

20. Pollock, D.; Cirpka, O.A. Fully coupled hydrogeophysical inversion of synthetic salt tracer experiments. Water Resour. Res. 2010, 46. [CrossRef]

21. Stesky, R.M. Electrical conductivity of brine-saturated fractured rock. Geophysics 1986, 51, 1585-1593. [CrossRef]

22. Shen, J.; Su, B.; Guo, N. Anisotropic characteristics of electrical responses of fractured reservoir with multiple sets of fractures. Pet. Sci. 2009, 6, 127-138. [CrossRef]

23. Roubinet, D.; Irving, J. Discrete-dual-porosity model for electric current flow in fractured rock. J. Geophys. Res. Solid Earth 2014, 119, 767-786. [CrossRef]

24. Wishart, D.N.; Slater, L.D.; Gates, A.E. Self potential improves characterization of hydraulically-active fractures from azimuthal geoelectrical measurements. Geophys. Res. Lett. 2006, 33, L17314. [CrossRef]

25. Maineult, A.; Thomas, B.; Nussbaum, C.; Wieczorek, K.; Gibert, D.; Lavielle, B.; Kergosien, B.; Nicollin, F.; Mahiouz, K.; Lesparre, N. Anomalies of noble gases and self-potential associated with fractures and fluid dynamics in a horizontal borehole, Mont Terri Underground Rock Laboratory. Eng. Geol. 2013, 156, 46-57. [CrossRef]

26. Berkowitz, B. Characterizing flow and transport in fractured geological media: A review. Adv. Water Resour. 2002, 25, 861-884. [CrossRef]

27. Gélis, C.; Revil, A.; Cushing, M.E.; Jougnot, D.; Lemeille, F.; Cabrera, J.; de Hoyos, A.; Rocher, M. Potential of Electrical Resistivity Tomography to Detect Fault Zones in Limestone and Argillaceous Formations in the Experimental Platform of Tournemire, France. Pure Appl. Geophys. 2010, 167, 1405-1418. [CrossRef]

28. Lesparre, N.; Boyle, A.; Grychtol, B.; Cabrera, J.; Marteau, J.; Adler, A. Electrical resistivity imaging in transmission between surface and underground tunnel for fault characterization. J. Appl. Geophys. 2016, 128, 163-178. [CrossRef]

29. Haas, A.K.; Revil, A.; Karaoulis, M.; Frash, L.; Hampton, J.; Gutierrez, M.; Mooney, M. Electric potential source localization reveals a borehole leak during hydraulic fracturing. Geophysics 2013, 78, D93-D113. [CrossRef]

30. DesRoches, A.J.; Butler, K.E.; MacQuarrie, K.T. Surface self-potential patterns related to transmissive fracture trends during a water injection test. Geophys. J. Int. 2018, 212, 2047-2060. [CrossRef]

31. Demirel, S.; Roubinet, D.; Irving, J.; Voytek, E. Characterizing Near-Surface Fractured-Rock Aquifers: Insights Provided by the Numerical Analysis of Electrical Resistivity Experiments. Water 2018, 10, 1117. [CrossRef]

32. Bernabe, Y. The transport properties of networks of cracks and pores. J. Geophys. Res. Solid Earth 1995, 100, 4231-4241. [CrossRef]

33. Roubinet, D.; Irving, J.; Pezard, P. Relating Topological and Electrical Properties of Fractured Porous Media: Insights into the Characterization of Rock Fracturing. Minerals 2018, 8, 14. [CrossRef]

34. Archie, G.E. The electrical resistivity $\log$ as an aid in determining some reservoir characteristics. Pet. Trans. AIME 1942, 146, 54-62. [CrossRef]

35. Overbeek, J. Electrochemistry of the Double Layer: In Colloid Science, Irreversible Systems; Kruyt, H R., Ed.; Elsevier: Amsterdam, The Netherlands, 1952.

36. Hunter, R.J. Zeta Potential in Colloid Science; Academic: New York, NY, USA, 1981. 
37. Pride, S. Governing equations for the coupled electromagnetics and acoustics of porous media. Phys. Rev. B 1994, 50, 15678-15696. [CrossRef]

38. Bernabé, Y. Streaming potential in heterogeneous networks. J. Geophys. Res. Solid Earth 1998, 103, 20827-20841. [CrossRef]

39. Morgan, F.D.; Williams, E.R.; Madden, T.R. Streaming potential properties of westerly granite with applications. J. Geophys. Res. 1989, 94, 12.449-12.461. [CrossRef]

40. Revil, A.; Pezard, P.A.; Glover, P.W.J. Streaming potential in porous media 1. Theory of the zeta potential. J. Geophys. Res. 1999, 104, 20021-20031. [CrossRef]

41. Glover, P.W.J.; Dery, N. Streaming potential coupling coefficient of quartz glass bead packs: Dependence on grain diameter, pore size, and pore throat radius. Geophysics 2010, 75, F225-F241. [CrossRef]

42. Kormiltsev, V.V.; Ratushnyak, A.N.; Shapiro, V.A. Three-dimensional modeling of electric and magnetic fields induced by the fluid flow movement in porous media. Phys. Earth Planet. Inter. 1998, 105, 109-118. [CrossRef]

43. Revil, A.; Leroy, P. Constitutive equations for ionic transport in porous shales. J. Geophys. Res. Solid Earth 2004, 109, B03208. [CrossRef]

44. Jougnot, D.; Roubinet, D.; Guarracino, L.; Maineult, A. Modeling streaming potential in porous and fractured media, description and benefits of the effective excess charge density approach. In Advances in Modeling and Interpretation in Near Surface Geophysics; Biswas, A., Sharma, S., Eds.; Springer: Berlin/Heidelberg, Germany, 2020.

45. Ishido, T.; Mizutani, H. Experimental and Theoretical Basis of Electrokinetic Phenomena in Rock-Water Systems and Its Applications to Geophysics. J. Geophys. Res. 1981, 86, 1763-1775. [CrossRef]

46. Jackson, M.D. Characterization of multiphase electrokinetic coupling using a bundle of capillary tubes model. J. Geophys. Res. Solid Earth 2008, 113, B04201. [CrossRef]

47. Linde, N. Comment on "Characterization of multiphase electrokinetic coupling using a bundle of capillary tubes model" by Mathew D. Jackson. J. Geophys. Res. Solid Earth 2009, 114, B06209. [CrossRef]

48. Jackson, M.D. Multiphase electrokinetic coupling: Insights into the impact of fluid and charge distribution at the pore scale from a bundle of capillary tubes model. J. Geophys. Res. Solid Earth 2010, 115, B07206. [CrossRef]

49. Revil, A.; Woodruff, W.F.; Lu, N. Constitutive equations for coupled flows in clay materials. Water Resour. Res. 2011, 47, W05548. [CrossRef]

50. Jougnot, D.; Linde, N.; Revil, A.; Doussan, C. Derivation of soil-specific streaming potential electrical parameters from hydrodynamic characteristics of partially saturated soils. Vadose Zone J. 2012, 11, 272-286. [CrossRef]

51. Jackson, M.; Leinov, E. On the Validity of the "Thin" and "Thick" Double-Layer Assumptions When Calculating Streaming Currents in Porous Media. Int. J. Geophys. 2012, 2012, 897807. [CrossRef]

52. Guarracino, L.; Jougnot, D. A Physically Based Analytical Model to Describe Effective Excess Charge for Streaming Potential Generation in Water Saturated Porous Media. J. Geophys. Res. Solid Earth 2018, 123, 52-65. [CrossRef]

53. Thanh, L.D.; Van Do, P.; Van Nghia, N.; Ca, N.X. A fractal model for streaming potential coefficient in porous media. Geophys. Prospect. 2018, 66, 753-766. [CrossRef]

54. Soldi, M.; Guarracino, L.; Jougnot, D. An analytical effective excess charge density model to predict the streaming potential generated by unsaturated flow. Geophys. J. Int. 2019, 216, 380-394. [CrossRef]

55. Soldi, M.; Guarracino, L.; Jougnot, D. An effective excess charge model to describe hysteresis effects on streaming potential. J. Hydrol. 2020, 588, 124949. [CrossRef]

56. Thanh, L.; Jougnot, D.; Do, P.; Ca, N.; Hien, N. A Physically Based Model for the Streaming Potential Coupling Coefficient in Partially Saturated Porous Media. Water 2020, 12, 1588. [CrossRef]

57. Shi, P.; Guan, W.; Hu, H. Dependence of Dynamic Electrokinetic-Coupling-Coefficient on the Electric Double Layer Thickness of fluid-filled porous formations. Ann. Geophys. 2018, 61. [CrossRef]

58. Erickson, D.; Li, D. Analysis of Alternating Current Electroosmotic Flows in a Rectangular Microchannel. Langmuir 2003, 19, 5421-5430. [CrossRef]

59. Wu, R.C.; Papadopoulos, K.D. Electroosmotic flow through porous media: cylindrical and annular models. Colloids Surfaces Physicochem. Eng. Asp. 2000, 161, 469-476.

60. Pascal, J.; Oyanader, M.; Arce, P. Effect of capillary geometry on predicting electroosmotic volumetric flowrates in porous or fibrous media. J. Colloid Interface Sci. 2012, 378, 241-250. [CrossRef]

61. Thanh, L.; Jougnot, D.; Do, P.; Mendieta, M.; Ca, N.; Hoa, V.X., Tan, P.M.; Hien, N.T. Electroosmotic coupling in porous media, a new model based on a fractal upscaling procedure. Transp. Porous Media 2020, 134, 249-274. [CrossRef]

62. Smoluchowski, M. Contribution à la théorie de l'endosmose électrique et de quelques phénomènes corrélatifs. Bull. Akad. Sci. Cracovie 1903, 8, 182-200.

63. Johnson, D.L.; Koplik, J.; Schwartz, L.M. New Pore-Size Parameter Characterizing Transport in Porous Media. Phys. Rev. Lett. 1986, 57, 2564-2567. [CrossRef]

64. Katz, A.J.; Thompson, A.H. Fractal Sandstone Pores: Implications for Conductivity and Pore Formation. Phys. Rev. Lett. 1985, 54, 1325-1328. [CrossRef]

65. Bo-Ming, Y. Fractal Character for Tortuous Streamtubes in Porous Media. Chin. Phys. Lett. 2005, 22, 158. [CrossRef]

66. Chelidze, T.; Gueguen, Y. Evidence of fractal fracture. Int. J. Rock Mech. Min. Sci. Geomech. Abstr. 1990, 27, 223-225. [CrossRef] 
67. Watanabe, K.; Takahashi, H. Fractal geometry characterization of geothermal reservoir fracture networks. J. Geophys. Res. Solid Earth 1995, 100, 521-528. [CrossRef]

68. Yu, B.; Cheng, P. A fractal permeability model for bi-dispersed porous media. Int. J. Heat Mass Transf. 2002, 45, 2983-2993. [CrossRef]

69. Roubinet, D.; Linde, N.; Jougnot, D.; Irving, J. Streaming potential modeling in fractured rock: Insights into the identification of hydraulically active fractures. Geophys. Res. Lett. 2016, 43, 4937-4944. [CrossRef]

70. Tyler, S.W.; Wheatcraft, S.W. Fractal processes in soil water retention. Water Resour. Res. 1990, 26, 1047-1054. [CrossRef]

71. Miao, T.; Yu, B.; Duan, Y.; Fang, Q. A fractal analysis of permeability for fractured rocks. Int. J. Heat Mass Transf. 2015, 81, 75-80. [CrossRef]

72. Wang, S.; Wu, T.; Cao, X.; Zheng, Q.; Ai, M. A fractal model for gas apparent permeability in microfractures of tight/shale reservoirs. Fractals 2017, 25, 1750036. [CrossRef]

73. Majumdar, A.; Bhushan, B. Role of Fractal Geometry in Roughness Characterization and Contact Mechanics of Surfaces. J. Tribol. 1990, 112, 205-216. [CrossRef]

74. Deng, P.; Zhu, J. Equivalent Permeability of Fractured Media Incorporating Tortuosity and Nonlinear Flow. Transp. Porous Media 2020, 132, 741-760. [CrossRef]

75. Torabi, A.; Berg, S.S. Scaling of fault attributes: A review. Mar. Pet. Geol. 2011, 28, 1444-1460. [CrossRef]

76. Ghanbarian, B.; Perfect, E.; Liu, H.H. A geometrical aperture-width relationship for rock fractures. Fractals 2019, $27,1940002$. [CrossRef]

77. Scheidegger, A.E. The Physics of Flow Through Porous Media. Soil Sci. 1958, 86, 355. [CrossRef]

78. Yu, B.; Liu, W. Fractal analysis of permeabilities for porous media. AIChE J. 2004, 50, 46-57. [CrossRef]

79. Thanh, L.D.; Jougnot, D.; Van Do, P.; Van Nghia A, N. A physically based model for the electrical conductivity of water-saturated porous media. Geophys. J. Int. 2019, 219, 866-876. [CrossRef]

80. Chung, C. Extrusion of Polymers 2E: Theory and Practice, 2nd ed.; Hanser Publications: Munich, Germany, 2010.

81. Neuzil, C.E.; Tracy, J.V. Flow through fractures. Water Resour. Res. 1981, 17, 191-199. [CrossRef]

82. Klimczak, C.; Schultz, R.; Parashar, R.; Reeves, D. Cubic law with aperture-length correlation: Implications for network scale fluid flow. Hydrogeol. J. 2010, 18, 851-862. [CrossRef]

83. Pfannkuch, H.O. On the Correlation of Electrical Conductivity Properties of Porous Systems with Viscous Flow Transport Coefficients. Dev. Soil Sci. 1972, 2, 42-54.

84. Waxman, M.H.; Smits, L.J.M. Electrical conductivities in oil bearing shaly sands. Soc. Pet. Eng. J. 1968, 8, 107-122. [CrossRef]

85. Revil, A.; Cathles III, L.M.; Losh, S.; Nunn, J.A. Electrical conductivity in shaly sands with geophysical applications. J. Geophys. Res. Solid Earth 1998, 103, 23925-23936. [CrossRef]

86. Friedman, S.P. Soil properties influencing apparent electrical conductivity: a review. Comput. Electron. Agric. 2005, 46, 45-70. [CrossRef]

87. Linde, N.; Binley, A.; Tryggvason, A.; Pedersen, L.B.; Revil, A. Improved hydrogeophysical characterization using joint inversion of cross-hole electrical resistance and ground-penetrating radar traveltime data. Water Resour. Res. 2006, 42. [CrossRef]

88. Glover, P. What is the cementation exponent? A new interpretation. Lead. Edge 2009, 28, 82-85. [CrossRef]

89. Brovelli, A.; Cassiani, G. Combined estimation of effective electrical conductivity and permittivity for soil monitoring. Water Resour. Res. 2011, 47. [CrossRef]

90. Rice, C.; Whitehead, R. Electrokinetic flow in a narrow cylindrical capillary. J. Phys. Chem. 1965, 69, 4017-4024. [CrossRef]

91. Pride, S.R.; Morgan, F.D. Electrokinetic dissipation induced by seismic waves. Geophysics 1991, 56, 914-925. [CrossRef]

92. Kirby, B.J.; Hasselbrink, E.F., Jr. Zeta potential of microfluidic substrates: 1. Theory, experimental techniques, and effects on separations. Electrophoresis 2004, 25, 187-202. [CrossRef]

93. Israelachvili, J. Intermolecular and Surface Forces; Academic Press: Cambridge, MA, USA, 1992.

94. Jougnot, D.; Mendieta, A.; Leroy, P.; Maineult, A. Exploring the Effect of the Pore Size Distribution on the Streaming Potential Generation in Saturated Porous Media, Insight From Pore Network Simulations. J. Geophys. Res. Solid Earth 2019, 124, 5315-5335. [CrossRef]

95. Hu, X.; Hu, S.; Jin, F.; Huang, S. Physics of Petroleum Reservoirs; Springer: Berlin/Heidelberg, Germany, 2017.

96. Rembert, F.; Jougnot, D.; Guarracino, L. A fractal model for the electrical conductivity of water-saturated porous media during mineral precipitation-dissolution processes. Adv. Water Resour. 2020, 145, 103742. [CrossRef]

97. Revil, A.; Linde, N.; Cerepi, A.; Jougnot, D.; Matthäi, S.; Finsterle, S. Electrokinetic coupling in unsaturated porous media. J. Colloid Interface Sci. 2007, 313, 315-327. [CrossRef]

98. Tiab, D.; Donaldson, E.C. Chapter 3-Porosity and Permeability. In Petrophysics, 4th ed.; Tiab, D., Donaldson, E.C., Eds.; Gulf Professional Publishing: Boston, MA, USA, 2016; pp. 67-186.

99. Erol, S.; Fowler, S.; Harcouët-Menou, V.; Laenen, B. An Analytical Model of Porosity-Permeability for Porous and Fractured Media. Transp. Porous Media 2017, 120, 327-358. [CrossRef]

100. Lamur, A.; Kendrick, J.; Eggertsson, G.; Wall, R.; Ashworth, J.; Lavallée, Y. The permeability of fractured rocks in pressurised volcanic and geothermal systems. Sci. Rep. 2017, 7. [CrossRef] [PubMed] 
101. Cherubini, A.; Garcia, B.; Cerepi, A.; Revil, A. Streaming Potential Coupling Coefficient and Transport Properties of Unsaturated Carbonate Rocks. Vadose Zone J. 2018, 17, 180030. [CrossRef]

102. Chilingarian, G.; Mazzullo, S.; Rieke, H. Carbonate Reservoir Characterization: A Geologic-Engineering Analysis, Part I; Elsevier Science: Amsterdam, The Netherlands, 1992. 